\title{
Climate Change Induced Vulnerability: Migration towards Cities
}

\author{
Rashadur Rahman ${ }^{1}$, Somashree Chattapadhya ${ }^{2}$ \\ ${ }^{I}$ (MEcon in Environmental Economics, Dhaka School of Economics, Bangladesh) \\ ${ }^{2}$ (MEcon in Environmental Economics, Dhaka School of Economics, Bangladesh)
}

\begin{abstract}
Bangladesh is one of the largest deltas of the world which stands in a very much climate vulnerable geographical location. The country is a low lying one and frequently tossed up by numbers of extreme environmental events such as flood, cyclone, draught, river erosion, sea level rise, salinity surrounded by others. These contribute huge destruction to lives and property and continuously increases the number of climate vulnerable people. Most of the time, after the devastating event, people loses almost everything and passes their days under the open sky. As the extreme events occur frequently, the number of affected people is also increasing in a continuous basis. A large portion of the affected people migrates towards the big cities to find their better survival. But the frequent movement towards cities is not a good sign for the long run. Every city has its own capacity to serve its citizen. Whenever the number of citizen goes beyond the capacity, certainly it will react. Now the question is how long the big cities like Dhaka can take this pressure and whenever it will fail then what will be the reaction of the city and how it will affect the citizens' life.

Keywords: Climate change, vulnerability, migration.
\end{abstract}

\section{Introduction}

As Bangladesh is a low lying country standing on the bank of Bay of Bengal so $1 \mathrm{~m}$ rise in sea level will lead to landless of 14.8 million people, loss of $29,846 \mathrm{sq}$. km. area and displacement of 40 million people. Impact of such climate change forces people to become displaced on permanent or long run basis (The Daily Star, 2011). Many of these displaced persons are moving towards capital city Dhaka and taking refuge in urban slums or other urban poverty pockets (The Daily Star, 2011). But the question is how long the city can tolerate this type of frequent migration and provides support because present population of Dhaka city is about 15 million which is expected to hit 20 million by 2025 ( Global Post, 2013). Aim of this paper is to discuss how extreme environmental events are increasing vulnerability in different areas and forces people to migrate in different cities especially Dhaka. Most of the time the environmental migrants migrate it a permanent basis initially and very few returns to their origin in the long run. Every year about 5 lakh people move towards Dhaka city from the coastal and other rural areas of the country where about 70 percent of the slum dwellers in Dhaka are forced by some kind of environmental shocks (IOM, 2010). So it is going to be a problem for the big cities like Dhaka to serve the huge population. This study tries to relate climate change, vulnerability and migration. Numbers of disasters are taken as reference here. At the same time the particular paper also tries to find out the reaction of cities due to frequent migration from the climate vulnerable areas. This essay also includes discussion on how the cities are at the end of their capacity to regenerate livelihood for huge population.

\section{Terminological Problems}

Different terms are used to notice the people who move for settlement due to extreme environmental events. Environmental migrants ${ }^{1}$ are those who leave their house temporarily or permanently due to the adverse effect of environmental change. The term refugee ${ }^{2}$ is very much related with race, religion, border, nationality etc. Again "Internally displaced person (IDP)" is defined by IOM in 2010 as "persons or groups of persons who have been forced or obliged to flee or to leave their homes or places of habitual residence, in particular as a result of or in order to avoid the effects of armed conflict, situations of generalized violence, violations of

\footnotetext{
${ }^{1}$ According to IOM, 2o1o, "persons or groups of persons who, for reasons of sudden or progressive changes in the environment that adversely affect their lives or living conditions, are obliged to leave their habitual homes, or choose to do so, either temporarily or permanently, and who move either within their country or abroad."

2 "owing to well-founded fear of persecution for reasons of race, religion, nationality, membership of a particular social group or political opinions, is outside the country of his nationality and is unable or, owing to such fear, is unwilling to avail himself of the protection of that country, or who, not having a nationality and being outside of the country of his former habitual residence as a result of such events, is unable or, owing to such fear, is unwilling to return to it"(IOM, 2010).
} 
human rights or natural or human-made disasters, and who have not crossed an internationally recognized State border" (IOM, 2010). So "Internally Displaced Person" is the appropriate term according to this context and the author uses IDP term through the paper.

\section{1 climate change}

\section{Climate Change Induced Vulnerability}

Climate change normally means the statistical deviation in the weather patterns over long periods which can be number of decades to millions of years. According to Oxford Dictionary, "changes in the earth's weather, including changes in temperature, wind patterns and rainfall, especially the increase in the temperature of the earth's atmosphere that is caused by the increase of particular gases, especially carbon dioxide". So it is such a global problem also can be seen only in a local climate pattern causes mainly due to huge atmospheric carbon dioxide production through random using of fossil fuels. But the thing is low lying countries like Bangladesh are standing in the most vulnerable position due to climate change. The survival of huge Bangladeshi people is in serious threat because of global warming and frequent natural disaster (MoEF, 2012). And these events show that the climate is changing.

\section{2 vulnerability}

According to IPCC Third Assessment Report, 2001 (cited in Islam. N, 2013) the term "vulnerability" means "the degree, to which a system is susceptible to, or unable to cope with, adverse effects of climate change, including climate variability and extremes".

The term vulnerability is combined with three components which are exposure, sensitivity and adaptive capacity. Vulnerability is a function of potential impact (I) and adaptive capacity (AC) where potential impact shows the combination of exposure and sensitivity and vulnerability results impact minus adaptive capacity.(Islam, 2013)

$\mathrm{V}=\mathrm{f}(\mathrm{I}-\mathrm{AC})$

Where,

Exposure $=$ Change in nature and degree of different climate variables

Sensitivity $=$ Reaction approach

Adaptive capacity $=\mathrm{AC}=$ Capacity of adaptation with the change

Potential impact $=\mathrm{I}=$ Exposure + Sensitivity

\section{3 climate changes induces vulnerability in Bangladesh}

Bangladesh has already experienced with frequent natural disasters which causes millions of population displacements. (Roy, n.d) It is most vulnerable country for massive tropical cyclone which attacks in every three years in an average and causes almost $60 \%$ of the total world's death due to tropical cyclone. These result huge lives, livelihoods, houses and infrastructural damages in the coastal areas (Kumar, U., Baten, A., et.al, 2010). The recent devastating cyclone that is named Aila can be regarded as a perfect example. It caused massive loss of properties, infrastructure, social and economic disruption, environmental degradation in the coastal areas of Bangladesh which costs death of 190 people and effect on 4.82 million in total 11 coastal districts (Roy, n.d). According to the ECHO partners" assessment, "about 40,000 people migrated due to Cyclone Aila from the Koyra upazila (sub-district) of Khulna District in Bangladesh". Where the number of migration due to Aila is about 30,000 in Paikgacha, 18,000 in Dacope and 12,000 in Batiaghata upazila (Roy, n.d). The affected people migrate towards the city areas of Khulna and the surrounding districts and the rate is continuing three families per day (Kumar, U., Baten, A., et.al, 2010). About 160 millions of people are highly vulnerable to climate change and sea level rise where around 35 millions of people will be displaced from 19 coastal districts of Bangladesh if sea level rises by one meter (Roy, n.d cited by Rabbani 2009). In the monsoon period of the year 2007, over 85,000 houses were damaged and 1.2 million acres of crops were destroyed (PPCR, 2010). Again draught, riverbank erosion, salinity etc. also hampers the normal life of the country people and throw them towards the vulnerability. Table 1 shows the results of different types of natural disaster occurred in different time.

\section{Migration Towards Cities}

Climate change causes frequent natural disaster which increases the vulnerability to the mass people of Bangladesh. Affected people lost everything sometimes even their lives and start fighting for their livelihood. They choose the migration option to be alive. In this circumstances job, shelter, basic needs safety etc. acts as a pull factor where the severity of destruction by natural disaster works as a push factor.

"Fig 1" and "Fig 2" shows different disaster prone areas of Bangladesh. In figure 1 the violet colored portion shows the cyclone prone areas of Bangladesh. Cyclones are created in the Bay of Bengal. So the coastal areas are in the danger zone where the dippiest color shows the highest risk and coastal areas are in that portion. As 
the colors become fed, the risks are also less and the areas far from the Bay of Bengal have low risk to be cyclone affected. Possibilities of different natural hazards are mapped in figure 2 where the deep yellow colored portion denotes the coastal zone that is very much low and almost $1 \mathrm{~m}$ high to the sea level. Again the bluish portion denotes the normal flood prone area where the magenta color says about flash flood. The fed red colored areas symbolize the severe draught prone areas. Figure 3 shows the internal migration pattern of Bangladesh.

According to figure 3 , the rate of out migration of the coastal areas like Borguna, Patuakhali, Bhola, Jhalokathi, Shatkhira etc. is huge and more than in migration. These are the most vulnerable areas of Bangladesh in the context of natural disaster like tidal cyclone and sea level rise. Again the rate of out migration is high in Kishoreganj, Narshingdi, Mymensingh etc. which are flood prone areas. The out migration rate is also high in Nawabganj, Naoga, Bogra etc. that are highly draught prone areas. So climate change, frequent natural disaster and climate vulnerable situation can be one of the causes of being the out migration rate high in that areas.

\section{Figures and Tables}

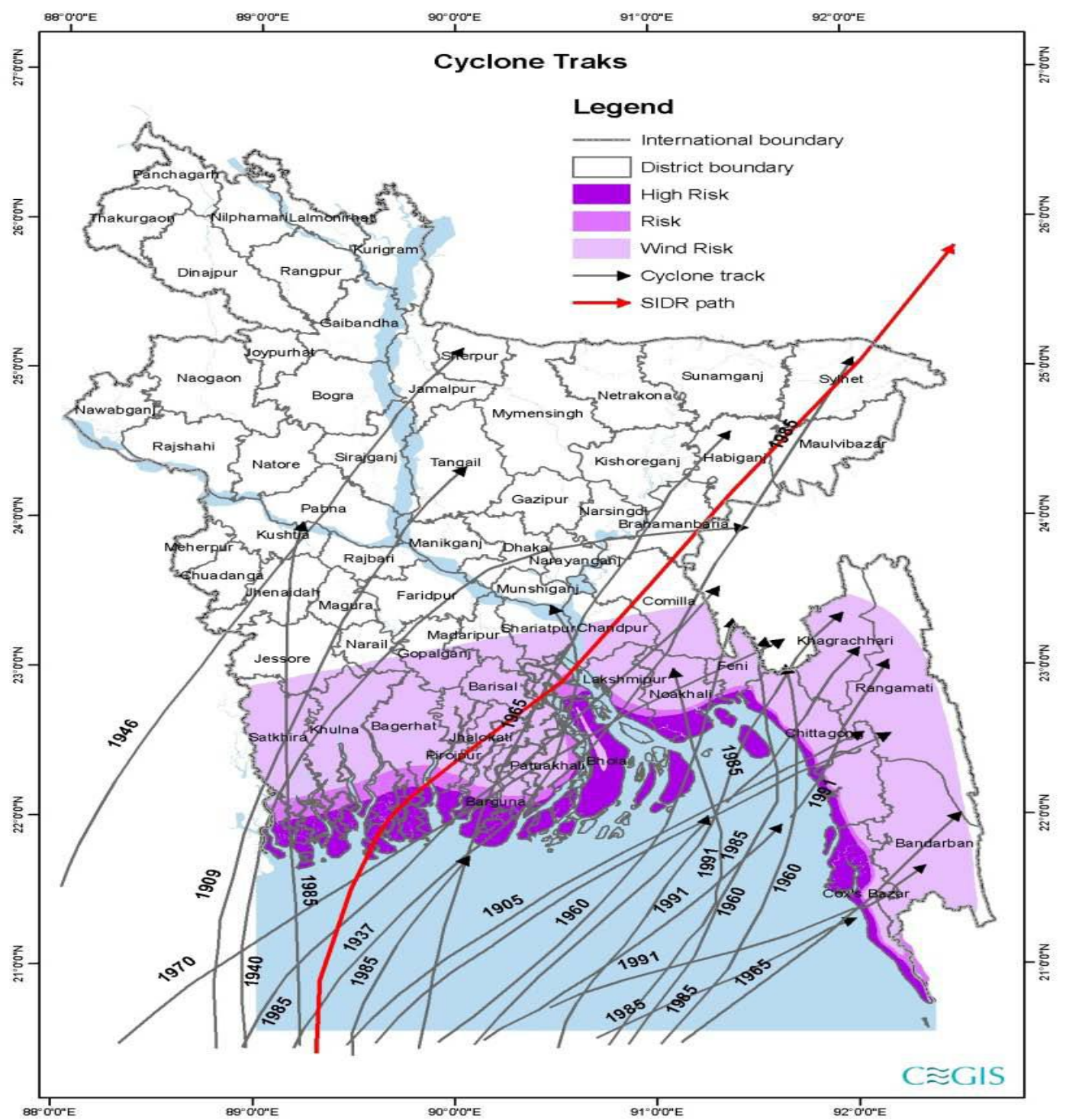

Figure 1: cyclone tracks of Bangladesh 


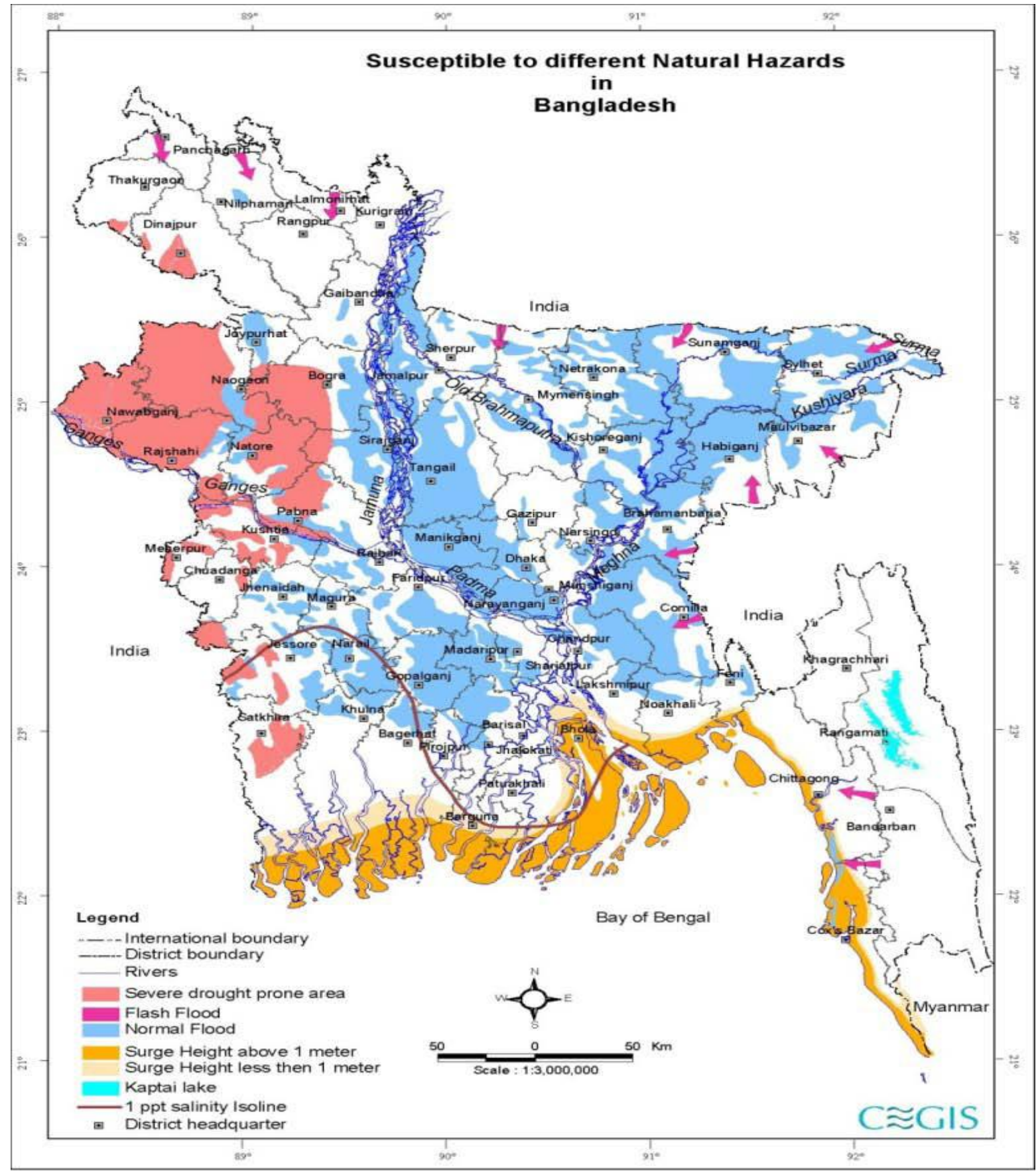

Figure 2: susceptible to different natural hazards in Bangladesh 


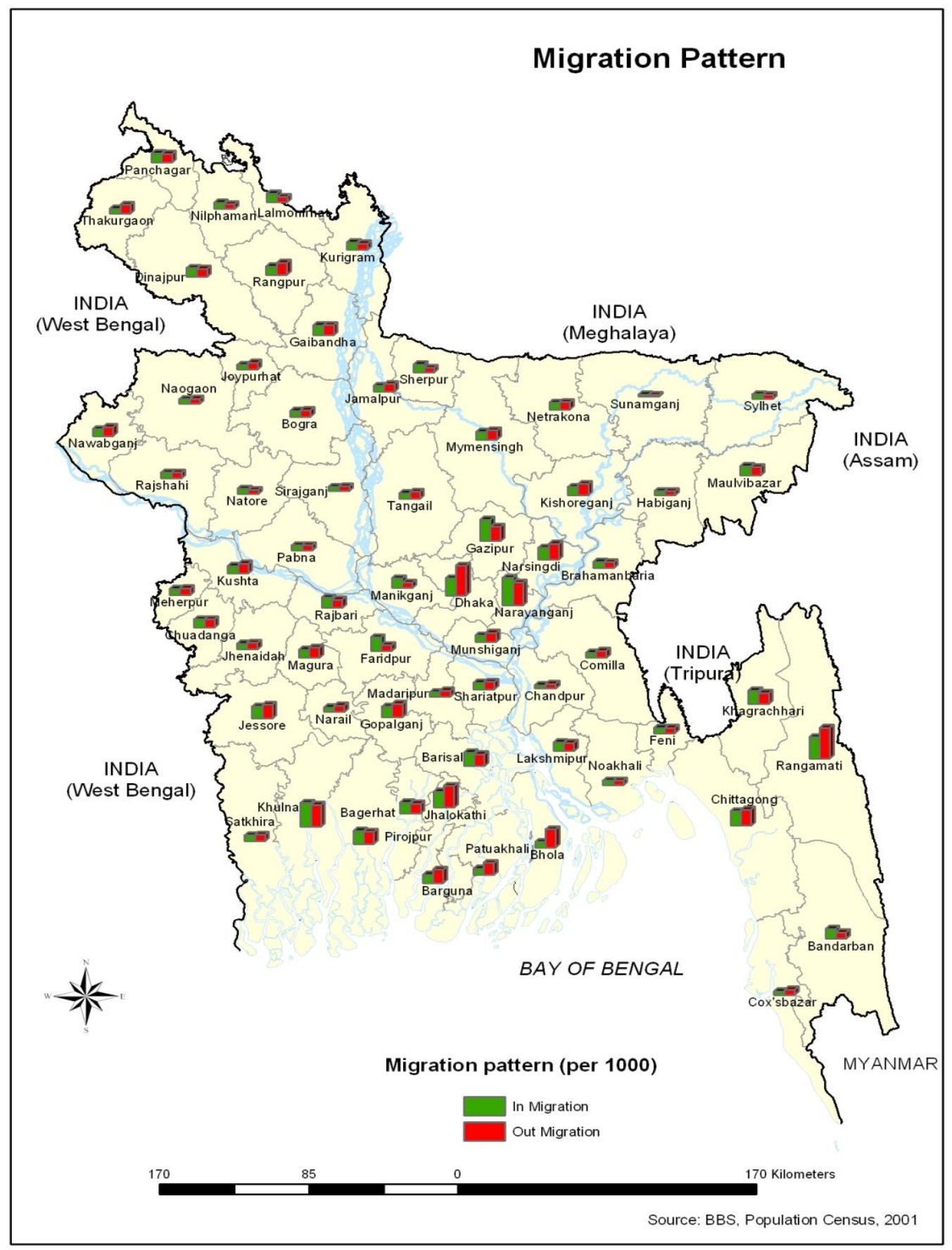

Figure 3: migration pattern of Bangladesh

Table 1: description of different types of natural disaster occurred in different time

\begin{tabular}{l|l|l}
\hline Disaster Type & Time & Affected People \\
\hline Flood & June, 1988 & $45,000,000$ \\
\hline Flood & June, 2004 & $36,000,000$ \\
\hline Flood & May, 1984 & $30,000,000$ \\
\hline Flood & July, 1987 & $29,700,000$ \\
\hline Flood & May, 1998 & $15,000,050$ \\
\hline Flood & July, 2007 & $13,771,380$ \\
\hline Flood & June, 1995 & $12,656,006$ \\
\hline Flood & January, 1993 & $11,469,537$ \\
\hline Disaster Type & Time & Death \\
\hline Flood & June, 1988 2 & 2,379 \\
\hline
\end{tabular}




\begin{tabular}{l|l|l}
\hline Flood & July, 1987 & 2,055 \\
\hline Flood & May, 1984 & 1,200 \\
\hline Flood & July, 2007 & 1,110 \\
\hline Flood & July, 1998 & 1,050 \\
\hline Cyclone & April, 1991 & 138,866 \\
\hline Cyclone & May, 1985 & 15,000 \\
\hline Cyclone SIDR & November, 2007 & 4,234 \\
\hline
\end{tabular}

Source: EM-DAT 2010 cited by Roy n.d.

\section{Reaction of Cities}

Cities in developing countries are in risk due to high density of population migrated from disaster prone areas which induce the cities to react. Every year about 5 lakh people move towards Dhaka city from coastal and other rural areas of the country and about 70 percent of the slum dwellers in Dhaka are forced by some kind of environmental shocks (IOM, 2010). But the city has its own capacity to accommodate people with basic needs and whenever the number of population exceeds the regenerative capacity, it starts to collapse. The capital city of Bangladesh is now starting to reacts which directly goes against the habitats. The city people are facing huge pollution where there stands excessive scarcity of pure drinking water. Lack of supply of pure drinking water; settlement problem of huge people, lack of adequate drainage system arises as big problems which is the main reason of increase in the number of slums. Widespread water logging during the monsoon has become a regular problem, is mainly causes by filling up the water bodies and by making the city concrete, which pollutes water and increases water borne diseases as well as Dengu, Maleria etc. in the logged water. Urban population will be forced to cope with incidents of air, water and noise pollution and the city is becoming a heat chamber (Tanner, T. et al, 2009). Cities are not ready to provide jobs for all. Most of the settlements of cities attract low income people engaged in cleaners, rickshaw pullers and day labors (Tanner, T. et al, 2009). So people are engaged in anti-social activities like smuggling begging etc. Traffic jam costs huge amount of time everyday from the life of the city people where the exhausted life is trying to find the destination and running towards peace. But the city itself is overburdened to serve the people. Over 35 years government of Bangladesh invests over 10 billion dollar to make the country less vulnerable to natural disaster (Tanner, T. et al, 2009). But to serve the IDP, now the city is facing vulnerable situation.

\section{Conclusion}

Bangladesh is geographically a disaster prone country. Due to climate change, a different type of disaster attacks frequently and costs severe destruction. After losing everything, affected people invest their hopes and moves towards cities to search their new destination. But the ecology of city is overburdened in terms of providing additional livelihood for its population. The question is how long the city will be able to take the pressure? Whenever the city will reach its 'breakeven point', if any, will fail to provide basic needs. To mitigate the vulnerability of the people, the mega cities like Dhaka itself becomes vulnerable to earthquake, fire, etc.

Based on overall discussion this paper tries to explain that there are two levels of vulnerability. At the very first level people in remote areas are exposed to environmental hazards and forced to move towards cities. Then people are exposed with second level of vulnerability in cities because our urbanization is not capable to accommodate with huge people.

\section{References}

[1]. Bangladesh Climate Change Strategy and Action Plan (2009). Ministry of Environment and Forest Government of the Peoples Republic of Bangladesh, ISBN: 984-8574-25-5.

[2]. Climate change induced displacement: Migration as an adaptation strategy. (2011, November 15). The Daily Star.

[3]. Global Post International News, (2013)."Who can solve a problem like Dhaka?" Retrived on 16 April 2013 from http://www.globalpost.com/

[4]. IOM, (2010). Assessing the Evidence: Environment, Climate Change and Migration in Bangladesh. ( Matthew Walsham,2010, p.22)

[5]. Islam, N. (2013, March). Vulnerability to Climate Change: Perspectives from Bangladesh. Paper presented at the Conference Hall, India-Arab Cultural CentreJMI, New Delhi.

[6]. Kumar, U., Baten, A., et.al (2010) Cyclone Aila: One Year on Natural Disaster to Human Sufferings. Unnayan Onneshan-The Innovators.

[7]. Litchfield, A (2010). Climate Change Induced Extreme Weather Events \& Sea Level Rise in Bangladesh leading to Migration and Conflict. ICE Case Studies, Number 229.

[8]. PPCR (2010). STRATEGIC PROGRAM FOR CLIMATE RESILIENCE BANGLADESH. Bangladesh: Strategic Program for Climate Resilience (SPCR), PPCR/SC.7/5

[9]. Roy, D.C. (n.d) Vulnerability and population displacements due to climate-induced disasters in coastal Bangladesh. Centre for Geoinformatics (Z_GIS), University of Salzburg, Hellbrunnerstrasse 34, A-5020 Salzburg, Austria. Retrieved on 20 March 2013.

[10]. Tanner, T. et.al (2009). Urban Governance for Adaptation: Assessing Climate Change Resilience in Ten Asian Cities. Institute of Development Studies at the University of Sussex Brighton BN1 9RE UKIDS WORKING PAPER 315 